\title{
Molecular Discrimination between Organic and Conventional Liquid Milk Products in Thailand Using ${ }^{1} \mathrm{H}-\mathrm{NMR}$ Metabolomics Approach
}

\author{
T. Phuenponga, M. Kongboonkird ${ }^{a}$, K. Duangmala,b, W. Lerdvorasapa , M. Suksawwawimon ${ }^{a}$, W. \\ Mekboonsonglarp $^{c}$, J. Nuamchit ${ }^{\mathrm{d}}$, N. Chantaprasarn ${ }^{\mathrm{d}}$, \& S. Settachaimongkon ${ }^{\mathrm{a}, \mathrm{b}, \mathrm{e}, \mathrm{w}}$ \\ ${ }^{a}$ Department of Food Technology, Faculty of Science, Chulalongkorn University, Bangkok 10330, Thailand \\ ${ }^{b}$ Emerging Processes for Food Functionality Design Research Unit, Chulalongkorn University, \\ Bangkok 10330, Thailand \\ 'Scientific and Technological Research Equipment Center (STREC), Chulalongkorn University, \\ Bangkok 10330, Thailand \\ ${ }^{\mathrm{d}}$ Dairy Research and Development Department, Dairy Farming Promotion Organization of Thailand (DPO), \\ Muak Lek, Saraburi 18180, Thailand \\ 'Omics Sciences and Bioinformatics Center, Faculty of Science, Chulalongkorn University, Bangkok 10330, Thailand \\ *Corresponding author: sarn.s@chula.ac.th \\ (Received 13-02-2021; Revised 27-04-2021; Accepted 03-05-2021)
}

\begin{abstract}
The aims of this study were to characterize and compare non-volatile polar metabolite profiles of organic and conventional liquid milk products using a non-targeted proton nuclear magnetic resonance ( $\left.{ }^{1} \mathrm{H}-\mathrm{NMR}\right)$ metabolomics approach. Pasteurized plain-liquid milk products from 10 different brands available in Thai marketplace were analyzed for their major chemical compositions and ${ }^{1} \mathrm{H}-\mathrm{NMR}$ derived metabolome data. Results demonstrated no specific trend for differentiation between organic and conventional milk samples based on their $\mathrm{pH}$, fat, protein, lactose, and milk solid-not-fat compositions. A total of 45 non-volatile polar metabolites in milk samples were identified by ${ }^{1} \mathrm{H}-\mathrm{NMR}$ technique. The chemometric analysis allowed discrimination between organic and conventional milk samples based on their ${ }^{1} \mathrm{H}-\mathrm{NMR}$ metabolite profiles. Changes in the relative concentration of formate, betaine, dimethyl sulfone, 2-oxoglutarate, creatine, pyruvate, butyrate, proline, acetoacetate, alanine, glycerophosphocholine, carnitine, and hippurate were statistically identified as potential biomarkers accountable for the discrimination between organic and conventional milk samples in this study. Variations of these compounds might be the reflections of animal diets, rumen fermentation, and physiological adaptation of the cows raised in organic dairy farming systems. Our findings provide new insights and support the effectiveness of using a non-targeted ${ }^{1} \mathrm{H}-\mathrm{NMR}$ combined with chemometrics to investigate the molecular authenticity of organic food products.
\end{abstract}

\section{Keywords: dairy; organic milk; food authentication; metabolomics; foodomics}

\section{INTRODUCTION}

Development in sustainable agriculture and adaptation to a more health-conscious market has increased the interest of consumers in organic food products and encouraged growth in this sector worldwide. In Thailand, it has been reported that consumers perceive organic foods as being healthier and more eco-friendly (Thongplew et al., 2016). During the past decades, organic labels have been progressively surged into many product categories in Thai marketplace, including milk and dairy products (Thongplew et al., 2016). To manage an organic dairy farm, particular requirements regarding livestock origins, conversion period to reach organic status, animal nutrition, animal housing, and free-range conditions, animal husbandry and health care along with the restricted usage of antibiotics and hormones in every stage of production, as well as manure and waste management need to be systematically maintained
(National Bureau of Agricultural Commodity and Food Standards (Thailand), 2011). Therefore, organic foods are generally considered "premium" and are being traded for much higher prices than conventional products due to higher production costs (Thongplew et al., 2016). To deliver appropriate quality assurance, analytical methods for verifying the authenticity of organically produced agricultural and food commodities are widely in demand.

It is well recognized that animal diets and farming practices in organic dairy products significantly influence the health status, physiological adaptation, and lactational performance of dairy cows (Schwendel et al., 2015). Alterations in milk yield, gross chemical composition (fat, protein, lactose, vitamins, and minerals), antioxidants, hormones, as well as agricultural traces present in organically produced milk have been extensively reported and are still inconclusive (Schwendel et al., 2015; Smigic et al., 2017). Progressively, comprehen- 
sive insights into the distinctive biomolecular profile or molecular fingerprint of organic milk have been unraveled from a metabolomics perspective using various advanced analytical technologies (Rocchetti et al., 2020; Tsiafoulis et al., 2019).

Metabolomics is one of omics technologies focusing on comprehensive characterization of small molecular weight metabolites (usually below $1.5 \mathrm{kDa}$ ) present in complex biological systems, including food matrices (Wishart, 2008). The applications of mass spectrometry (MS) and nuclear magnetic resonance (NMR) based metabolomics have been well acknowledged in molecular authentication of organically produced agricultural and food commodities from various plant and animal origins (Capuano et al., 2013; Vallverdú-Queralt \& Lamuela-Raventós, 2016). Regarding milk and dairies, many studies have focused on alterations in the lipid components, especially fatty acids, of products since they are primarily influenced by different feeding regimens between organic and conventional farming systems (Capuano et al., 2015; Liu et al., 2020; Schwendel et al., 2015). Besides lipid components, alterations in several polar metabolites have been reported in association with the organic status of bovine milk (Schwendel et al., 2015), but the information is rather limited (Boudonck et al., 2009; Erich et al., 2015; Rocchetti et al., 2020). To the authors' best knowledge, research on the influence of organic dairy production on the metabolome of raw and retail milk produced in tropical regions is even more scarce. This information is particularly essential since variations in milk metabolites are also the direct reflections of animal diets, rumen fermentation, and physiological adaptation of the cows raised in organic farming systems.

Therefore, this study aimed to characterize and compare non-volatile polar metabolite profiles of organic and conventional liquid milk products available in Thai marketplace using a high-resolution proton nuclear magnetic resonance ( $\left.{ }^{1} \mathrm{H}-\mathrm{NMR}\right)$ spectroscopy. The metabolite profiles among samples were statistically compared by means of chemometric analysis. Finally, potential biomarker metabolites accountable for the discrimination between organic and conventional liquid milk products were proposed.

\section{MATERIALS AND METHODS}

\section{Collection of Retail Milk Samples}

Ten different brands of liquid milk products were selected based on the reputation of the company in Thai marketplace. A total of 73 pasteurized plain (cow) milk samples were purchased from retail stores in Bangkok metropolitan area during July-August 2020. The experiment was set as a completely randomized design comprising 10 treatments (product brands) with a different number of replicates. However, at least three biological replicates from different batches of production, assumed by different expiration dates on the package, were included for each brand. In total, the collective set of samples comprised 24 conventional milk samples from six brands (Brand A-F) and 49 organic milk samples from four brands (Brand G-J). It should be mentioned that all organic milk samples in this study were commercialized with the "Organic Thailand" certification emblem issued by the National Bureau of Agricultural Commodity and Food Standards. Upon arrival to the laboratory, each sample was divided into two portions. To determine major chemical composition, samples were stored at 4 ${ }^{\circ} \mathrm{C}$ and analyzed on the next day. For ${ }^{1} \mathrm{H}-\mathrm{NMR}$ analysis, samples were stored at $-35{ }^{\circ} \mathrm{C}$ and subjected to the analysis within four weeks.

\section{Determination of $\mathrm{pH}$ and Major Chemical Composition}

The $\mathrm{pH}$ of samples was determined using a laboratory $\mathrm{pH}$ meter (S230, Mettler Toledo, USA). The major chemical composition, including fat, protein, lactose, milk solids not fat (SnF), and total solids (TS) content (\%wt.) of samples, was determined using a MilkoScan ${ }^{\mathrm{TM}}$ FT+ analyzer (FOSS, Hillerød, Denmark).

\section{Sample Preparation and ${ }^{1} \mathrm{H}-\mathrm{NMR}$ Analysis}

Frozen samples were thawed at room temperature for $30 \mathrm{~min}$ and mixed rigorously. The $\mathrm{pH}$ was verified to ensure that there was no deterioration occurred during storage. Samples were then adjusted to $\mathrm{pH} 6.0$ using 1.0 NHCl. Cream separation, lipid residues removal by dichloromethane extraction, and protein fractions removal by ultra-centrifugation were performed as described in our previous study (Luangwilai et al., 2021). The milk serum was collected and filtered through a centrifugal device with $3 \mathrm{kDa}$ molecular weight cutoffs (Pall Nanocep ${ }^{\circledR}$, Pall Life Sciences, Ann Arbor, MI). The filtrate was then diluted 1:1 (v/v) with phosphate buffer pH 6.0 consisting of $1 \mathrm{mM}$ 3-(Trimethylsilyl) propionic-2, 2, 3, 3-d4 acid sodium salt (TSP) (Merck, Darmstadt, Germany) as a standard internal compound. Finally, the mixture $(400 \mu \mathrm{L})$ was subjected to a 500 MHz NOESY-GPPR-1D- ${ }^{1} \mathrm{H}-\mathrm{NMR}$ spectrometer (Bruker, Rheinstetten, Germany) operated under the same condition as Luangwilai et al. (2021).

\section{${ }^{1}$ H-NMR Spectra Processing and Data Acquisition}

${ }^{1} \mathrm{H}-\mathrm{NMR}$ spectra were corrected, pre-treated, and processed through binning technique (0.02 ppm interval) (Luangwilai et al., 2021). Metabolites present in the samples were identified using Chenomx NMR suite 8.2 library (Chenomx Inc., Canada), Livestock Metabolome Database (https://lmdb.ca/), Bovine Metabolome Database (https://bovinedb.ca/), Milk Composition Database (https://mcdb.ca/), and kinds of literature (Foroutan et al., 2019; Foroutan et al., 2020; Goldansaz et al., 2017; Li et al., 2017; Luangwilai et al., 2021; Settachaimongkon et al., 2021; Settachaimongkon et al., 2017; Tenori et al., 2018). The sum of signal intensities (arbitrary units) from all bins accountable for each respective metabolite was introduced to chemometric analysis (Settachaimongkon et al., 2014). 


\section{Statistical Analysis}

Analysis of variance (ANOVA) combined with multiple comparisons by Tukey's test was performed using SPSS statistical package ver.22.0 (SPSS Inc., Chicago, IL, USA). A significantly different level was considered at $\mathrm{p} \leq 0.05$. ${ }^{1} \mathrm{H}-\mathrm{NMR}$ metabolomics data were normalized against the internal standard, median centering, and $\log _{2}$ scaling before subjecting to multivariate statistical analysis (Settachaimongkon et al., 2014). Heat-map visualization combined with Pearson's correlationbased hierarchical clustering (HCA), principal component analysis (PCA), and partial least-squares-discriminant analysis (PLS-DA) were performed using Multi-Experiment Viewer (http://mev.tm4.org) and MetaboAnalyst software package (www.metaboanalyst. ca). The quality of the PLS-DA model was expressed by $R^{2}$ (accuracy) and $Q^{2}$ values (predictability) derived from leave-one-out cross-validation (LOOCV) test. Finally, metabolites with variable importance in projection (VIP) score $>1.0$ and $p \leq 0.05$ were considered to be potential biomarkers responsible for the discrimination (Luangwilai et al., 2021).

\section{RESULTS}

\section{Variations in Major Chemical Composition and $\mathrm{pH}$ of Samples}

The major chemical composition, including fat, protein, lactose, SnF, and TS contents of organic and conventional milk samples, are presented in Table 1. Results demonstrated that the samples' fat, protein and lactose contents ranged between $3.50-5.48 \%, 3.02-3.45 \%$, and $4.04-4.68 \%$, respectively. The significantly highest fat, protein, and lactose contents were found in brands $\mathrm{H}, \mathrm{A}$, and G samples. Subsequently, variations in the SnF and TS content of samples were reliant on the abundances of these three major components. The three highest milk TS contents were found in samples from brands $\mathrm{H}, \mathrm{C}$, and $\mathrm{F}$, respectively, and two of them were conventional products. The $\mathrm{pH}$ values of all samples ranged between 6.67-6.77. Although significant differences in the major chemical composition and $\mathrm{pH}$ among samples could be statistically determined, none of the tendency for discrimination between organic and conventional milk samples could be noticed based on these gross profiles.

\section{${ }^{1}$ H-NMR Metabolomic Data Acquisition, Metabolite Identification, and Chemometric Analysis}

Chemical shift viability across the ${ }^{1} \mathrm{H}-\mathrm{NMR}$ spectrum was acquired using a 0.02 ppm interval size binning technique. The signal intensity in each bin was integrated and expressed in arbitrary units. Metabolite identification labels were assigned to the bins by consulting metabolome databases and relevant kinds of literature. Moreover, eight standard reference compounds were also added $(1.0 \mathrm{mM})$ to a QC milk sample to verify the identification process in Chenomx software (data not shown). As a result, 178 bins were accountable for identifying 45 metabolites, including amino acids, carbohydrates, carbonyl compounds, organic acids, and lipid derivatives in retail milk samples of this study (Figure 1). ${ }^{1} \mathrm{H}-\mathrm{NMR}$ signal intensities of these compounds were introduced as variables in the chemometric analysis.

A non-supervised Pearson's correlation-based hierarchical clustering combined with heat-map visualization was performed to evaluate the similarity of ${ }^{1} \mathrm{H}-\mathrm{NMR}$ metabolite profiles between organic and conventional milk samples $(n=73)$ (Figure 2$)$. Results showed that conventional milk samples from brands $\mathrm{A}, \mathrm{B}, \mathrm{C}$, and D were grouped into different clusters (cluster A) from organic milk samples (cluster B, C, and D) according to their ${ }^{1} \mathrm{H}-\mathrm{NMR}$ metabolite profiles. Nevertheless, it could be seen that this clear distinction was not accountable for the conventional milk from brands E and F, where their metabolite profiles seemed to be rather integrated with those of organic milk samples. Moreover, a very diversity among the metabolite profiles within the group of samples from brands $\mathrm{E}$ and $\mathrm{F}$ was remarkable. Large variations among the metabolite profiles of samples were evident in all brands of organic milk products. This observation could be presumably related to the large numbers of their samples included in the analysis. Besides the sample clusters revealed by the dendrogram, different colors in the heat-map indicate the relative quantification of non-volatile metabolites. The red color indicates a higher abundance, and the green color indicates a lower abundance of metabolites among samples. Results showed that most metabolites were present in the relatively higher abundances in samples grouped in clusters $\mathrm{B}$ and $\mathrm{C}$ compared to those located in clusters A and D. The integrated ${ }^{1} \mathrm{H}-\mathrm{NMR}$ signal intensities expressed

Table 1. Major chemical composition and $\mathrm{pH}$ of organic and conventional liquid milk samples

\begin{tabular}{|c|c|c|c|c|c|c|c|c|c|c|}
\hline \multirow{2}{*}{$\begin{array}{l}\text { Milk } \\
\text { properties }\end{array}$} & \multicolumn{6}{|c|}{ Conventional milk products } & \multicolumn{4}{|c|}{ Organic milk products } \\
\hline & Brand A & Brand B & Brand C & Brand D & Brand E & Brand F & Brand G & Brand $\mathrm{H}$ & Brand I & Brand J \\
\hline Fat (\%) & $3.77 \pm 0.02^{\mathrm{d}}$ & $3.58 \pm 0.02^{\mathrm{d}}$ & $4.47 \pm 0.02^{b}$ & $4.34 \pm 0.04^{\mathrm{bc}}$ & $3.52 \pm 0.02^{\mathrm{d}}$ & $3.87 \pm 0.02^{\mathrm{cd}}$ & $3.56 \pm 0.04^{\mathrm{d}}$ & $5.48 \pm 0.02^{\mathrm{a}}$ & $3.50 \pm 0.02^{\mathrm{d}}$ & $3.77 \pm 0.6^{\mathrm{d}}$ \\
\hline Protein (\%) & $3.45 \pm 0.02^{\mathrm{a}}$ & $3.07 \pm 0.02^{\mathrm{b}}$ & $3.43 \pm 0.02^{\mathrm{a}}$ & $3.03 \pm 0.02^{\mathrm{b}}$ & $3.07 \pm 0.02^{\mathrm{b}}$ & $3.06 \pm 0.02^{\mathrm{b}}$ & $3.03 \pm 0.02^{\mathrm{b}}$ & $3.02 \pm 0.02^{\mathrm{b}}$ & $3.05 \pm 0.02^{\mathrm{b}}$ & $3.04 \pm 0.02^{\mathrm{b}}$ \\
\hline Lactose $(\%)$ & $4.04 \pm 0.02^{\mathrm{d}}$ & $4.37 \pm 0.02^{\mathrm{c}}$ & $4.56 \pm 0.02^{\mathrm{ab}}$ & $4.54 \pm 0.03^{\mathrm{ab}}$ & $4.46 \pm 0.03^{\mathrm{b}}$ & $4.48 \pm 0.03^{\mathrm{b}}$ & $4.68 \pm 0.02^{\mathrm{a}}$ & $4.36 \pm 0.02^{\mathrm{c}}$ & $4.63 \pm 0.03^{\mathrm{a}}$ & $4.38 \pm 0.02^{\mathrm{c}}$ \\
\hline SnF (\%) & $7.49 \pm 0.02^{\mathrm{cd}}$ & $7.46 \pm 0.02^{\mathrm{d}}$ & $8.02 \pm 0.02^{\mathrm{a}}$ & $7.58 \pm 0.02^{c}$ & $7.53 \pm 0.04^{\mathrm{c}}$ & $7.54 \pm 0.02^{c}$ & $7.71 \pm 0.02^{b}$ & $7.39 \pm 0.02^{\mathrm{e}}$ & $7.68 \pm 0.02^{b}$ & $7.44 \pm 0.04^{\text {de }}$ \\
\hline TS (\%) & $11.29 \pm 0.03^{\mathrm{e}}$ & $11.04 \pm 0.02^{\mathrm{g}}$ & $12.48 \pm 0.02^{\mathrm{b}}$ & $11.90 \pm 0.03^{c}$ & $11.03 \pm 0.03^{\mathrm{g}}$ & $11.39 \pm 0.03^{\mathrm{d}}$ & $11.27 \pm 0.02^{\mathrm{e}}$ & $12.86 \pm 0.03^{a}$ & $11.19 \pm 0.02^{\mathrm{f}}$ & $11.20 \pm 0.03^{f}$ \\
\hline $\mathrm{pH}$ & $6.69 \pm 0.02^{b c}$ & $6.68 \pm 0.02^{\mathrm{bc}}$ & $6.70 \pm 0.02^{\mathrm{bc}}$ & $6.70 \pm 0.01^{\mathrm{bc}}$ & $6.77 \pm 0.03^{\mathrm{a}}$ & $6.73 \pm 0.02^{\mathrm{ab}}$ & $6.70 \pm 0.02^{\mathrm{bc}}$ & $6.70 \pm 0.01^{\mathrm{bc}}$ & $6.68 \pm 0.01^{b c}$ & $6.67 \pm 0.02^{c}$ \\
\hline
\end{tabular}

Note: $\mathrm{SnF}=$ milk solids not fat; TS= total solids. Values are the average of samples \pm SD. Means in the same row with different superscripts differ significantly $(\mathrm{p} \leq 0.05)$. 
A

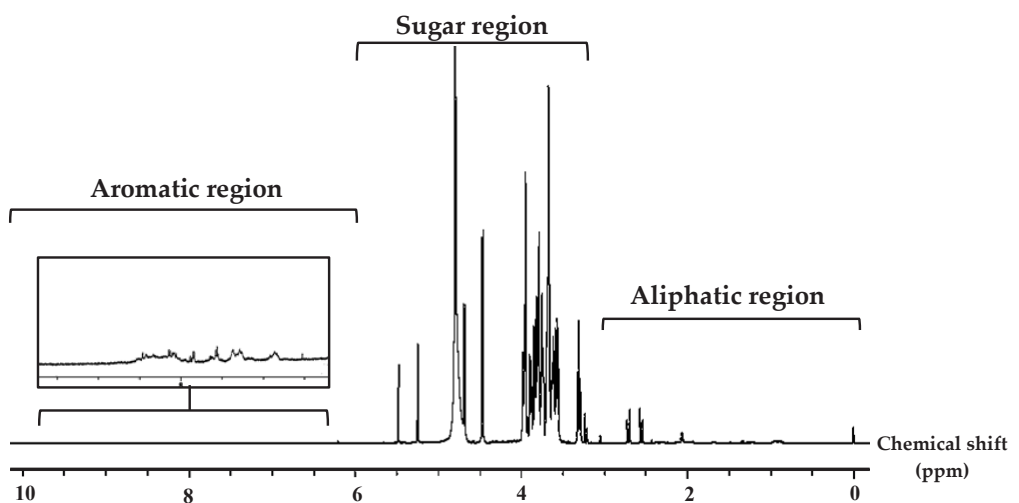

B

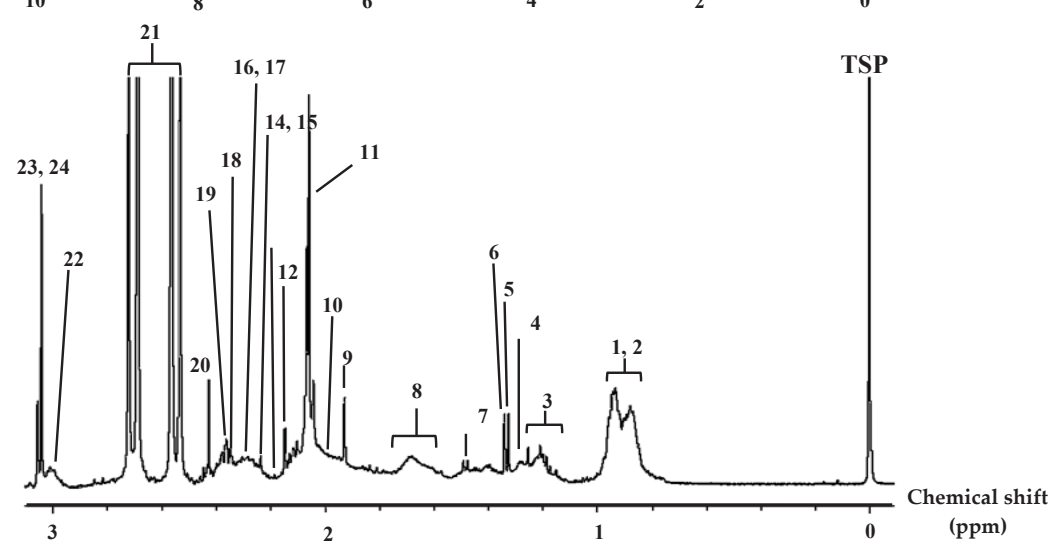

C

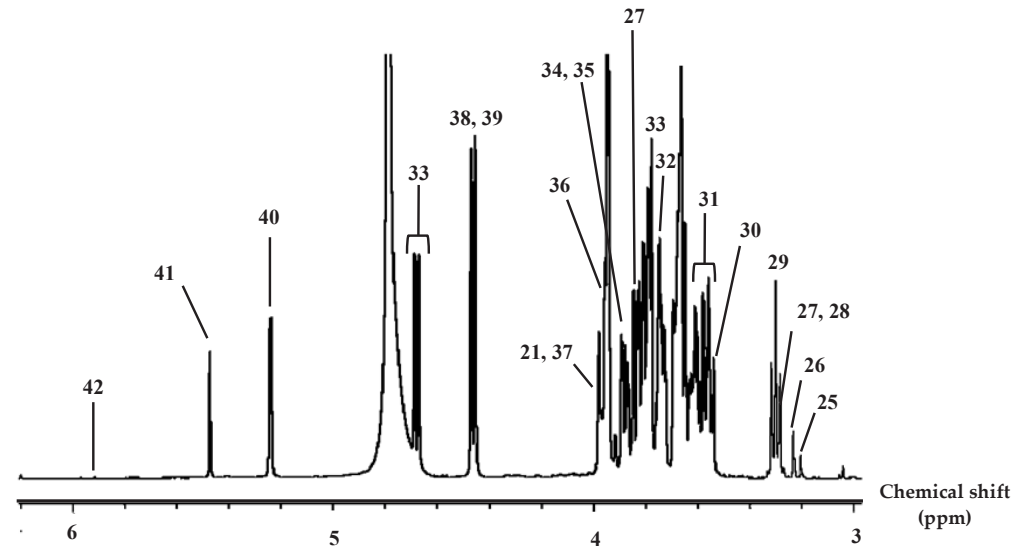

D

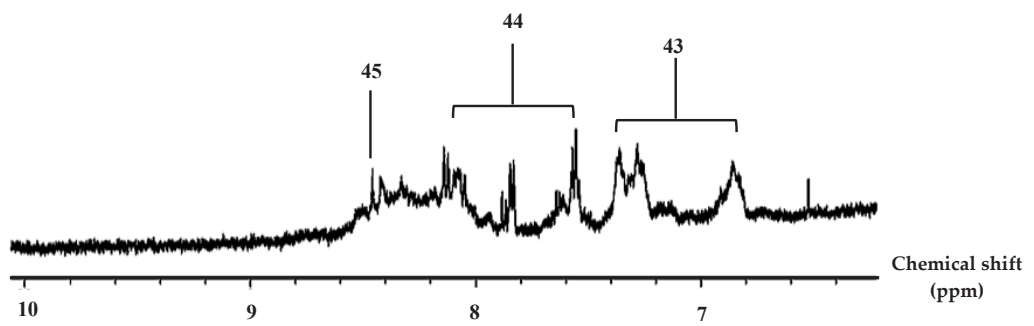

Figure 1. Representative ${ }^{1} \mathrm{H}-\mathrm{NMR}$ spectra of a pasteurized liquid milk sample (panel A) and expansions corresponding for aliphatic region (panel B), sugar region (panel C), and aromatic region (panel D) with assigned peaks: TSP : internal standard, 1: valerate derivatives, 2: isoleucine, 3: ethanol, 4: 2-octanoate, 5: threonine, 6: lactate, 7: alanine, 8: $\beta$-hydroxybutyrate, 9: acetate, 10: isovalerate, $11: \mathrm{N}$-acetyl amino acids, 12: butyrate, 13 : valine, 14: acetoacetate, 15: hydroxyisovalerate, 16: 2-oxoglutarate, 17: proline, 18: pyruvate, 19: succinate, 20: acetylcarnithine, 21: citrate, 22: creatine phosphate, 23: creatinine, 24: creatine, 25: dimethyl sulfone, 26: betaine, 27: glycerolphosphocholine, 28: carnitine, 29: O-phosphocholine, 30: propylene glycol, 31: glucose, 32: 1,6-anhydro- $\beta$-D-glucose, 33: lactose, 34: galactose, 35: methionine, 36: $N$-acetylglucosamine, 37: choline, 38: 1,3-dihydroxyacetone, 39: $O$-acetylcholine, 40: sugar residue, 41: ribose, 42: uridine, 43: amino acid residues, 44: hippurate, and 45: formate. 


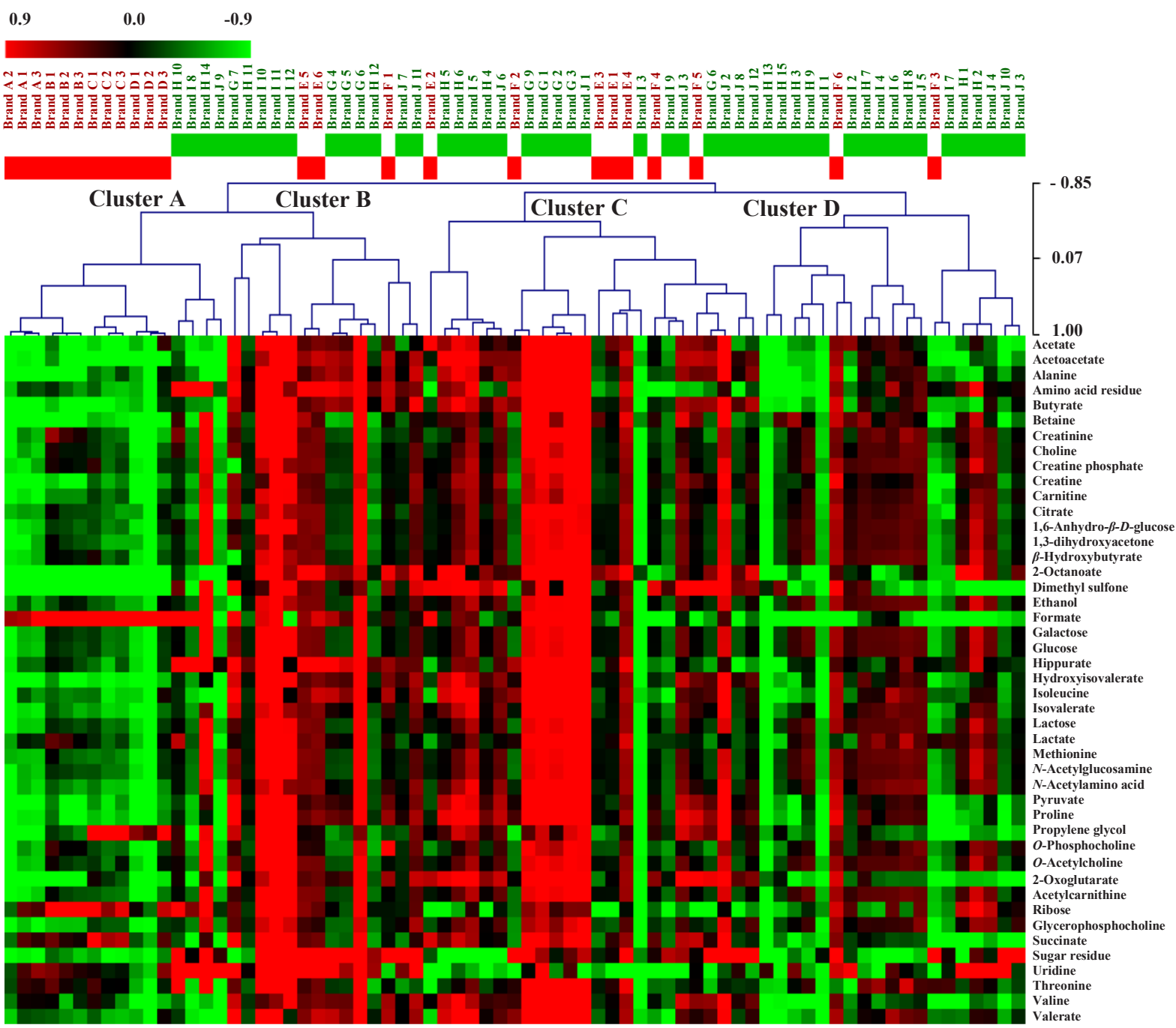

Figure 2. Heat-map visualization and hierarchical clustering of ${ }^{1} \mathrm{H}-\mathrm{NMR}$ derived non-volatile polar metabolite profiles of organic $(\square)$ and conventional $(\square)$ liquid milk samples. The dendrogram represents sample clusters based on Pearson's correlation coefficient with average linkage. Each square in the heat-map expresses normalized metabolite content respected to the color range. The red color indicates higher content of the corresponding compound. For interpretation of the references to color in this figure, the reader is referred to the web version of this article and the relative quantification of metabolites in Table 2.

in $\log _{10}$ transformed [arbitrary unit] of all metabolites were statistically compared using one-way ANOVA (Settachaimongkon et al., 2014) and presented in Table 2.

Supervised pattern recognition by PLS-DA was performed to discriminate the ${ }^{1} \mathrm{H}-\mathrm{NMR}$ metabolite profiles between organic and conventional milk samples $(n$ = 73) (Figure 3). The first two components constructed an overall PLS-DA score plot with $R^{2}=0.767$ and $Q^{2}=$ 0.583 (Figure 3A). Results showed a good distinction between conventional milk samples (marked in red) of brand A-D and organic milk samples (marked in green) along with component 1 (52.60\%). In agreement with the HCA result, PLS-DA pattern showed that ${ }^{1} \mathrm{H}-\mathrm{NMR}$ metabolite profiles of conventional milk samples from brand E-F were mostly overlapped with those of organic milk samples, notably in the center of the plot and therefore could not be visibly distinguished (Figure 3A). VIP scores with a value greater than 1.0 and $\mathrm{p} \leq 0.05$ suggested that formate, betaine, dimethyl sulfone, 2-oxoglutarate, creatine, pyruvate, butyrate, proline, acetoacetate, alanine, glycerophosphocholine, carnitine, and hippurate were potential biomarker metabolites accountable for the discrimination between organic and conventional milk products in this study (Figure 3B). The relative abundances of these compounds were demonstrated in a comparative box-whisker plot summary (Figure 3C).

For evaluating the variation among different brands, two separated PLS-DA score plots were constructed to discriminate the ${ }^{1} \mathrm{H}-\mathrm{NMR}$ metabolite profiles within the group of conventional milk samples $(n=24)$ with $R^{2}=0.876$ and $Q^{2}=0.751$ (Figure $4 \mathrm{~A}$ ) and within the group of organic milk samples $(n=49)$ with $R^{2}=0.567$ and $Q^{2}=0.253$ (Figure $4 \mathrm{~B}$ ). Within the group of conventional milk, samples were separated into two groups along with component 1 (58.80\%). The first group consisted of samples from brand A-D where good distinctions among brands could be observed. Another group consisted of samples from brand E-F with relatively comparable ${ }^{1} \mathrm{H}-\mathrm{NMR}$ metabolite profiles (Figure $4 \mathrm{~A}$ ). Within the group of organic milk, no clear distinction 


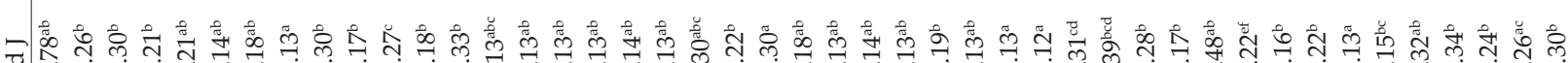

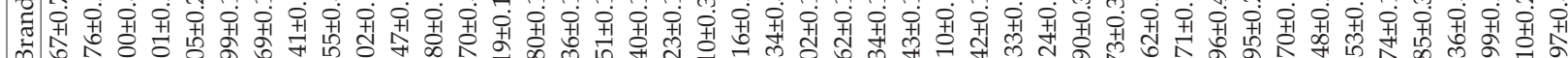

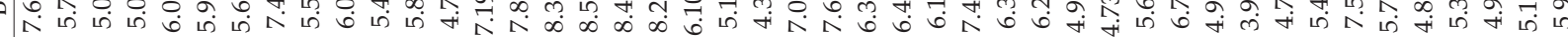

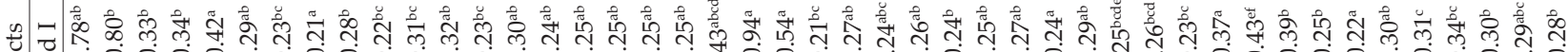

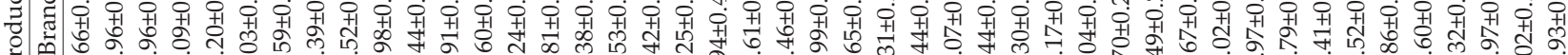
禀

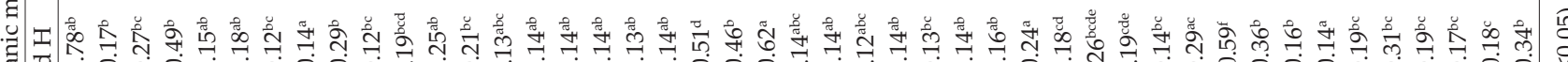

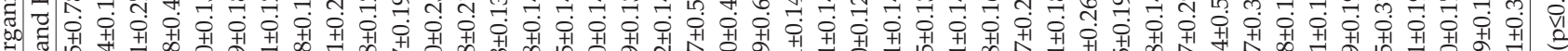

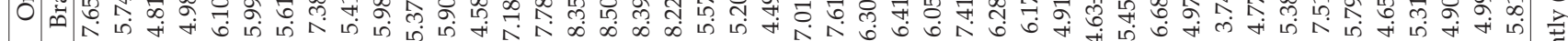

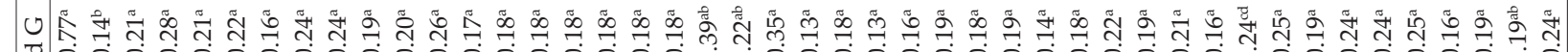

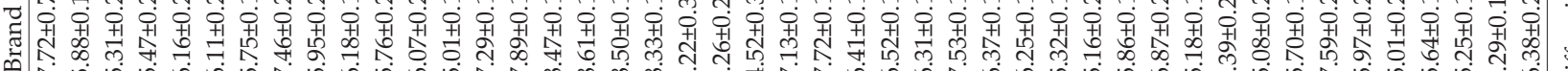

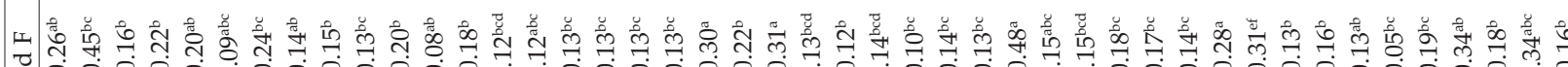

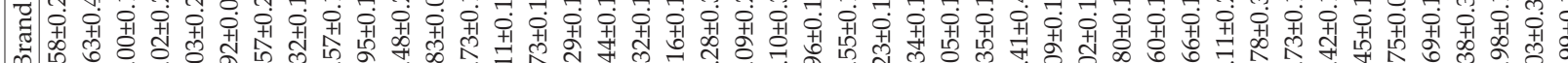

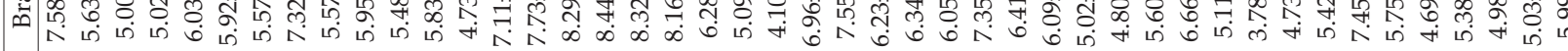

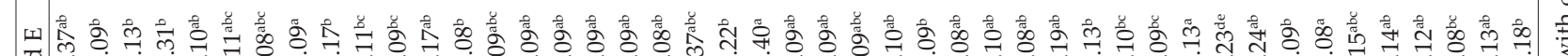

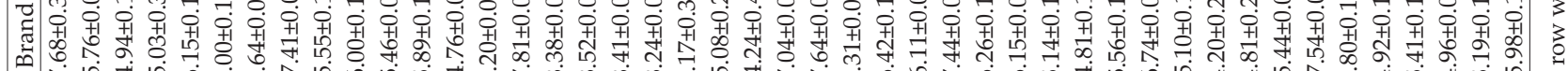

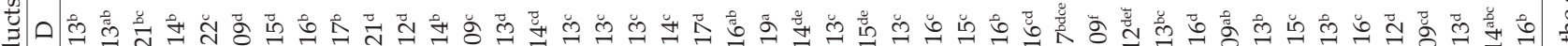

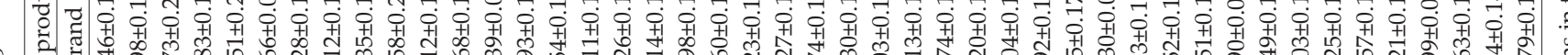

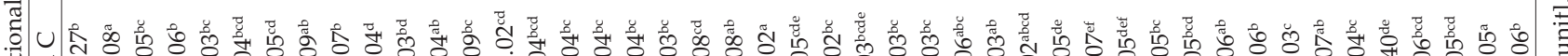

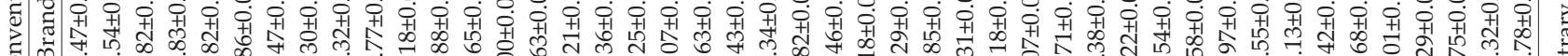

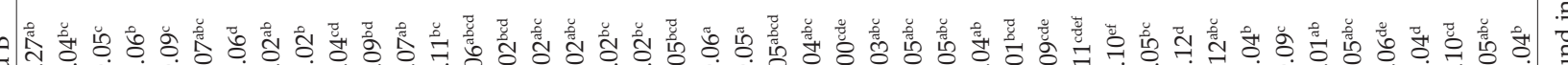

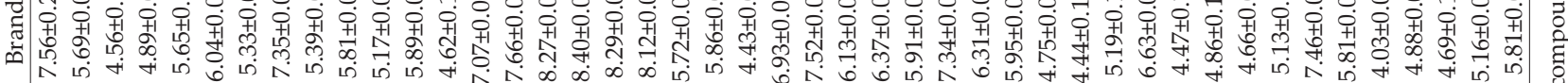

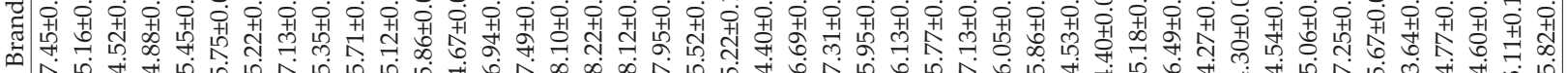<smiles>C1CCCCC1</smiles> 
A

PLS-DA Score Plot
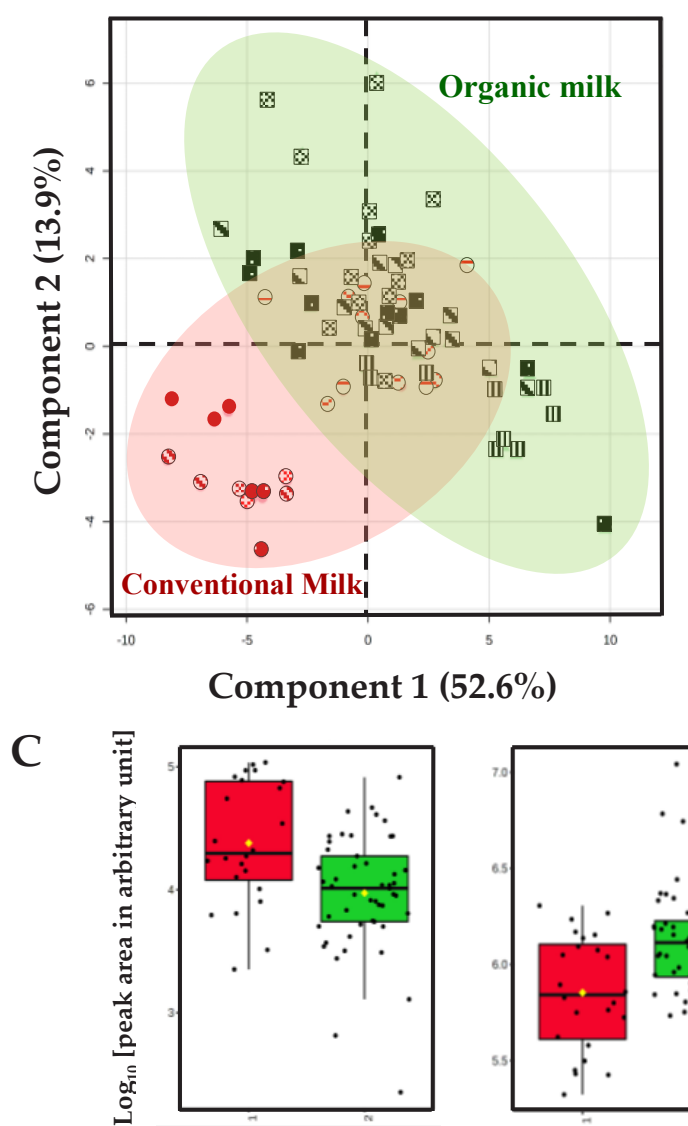

Formate

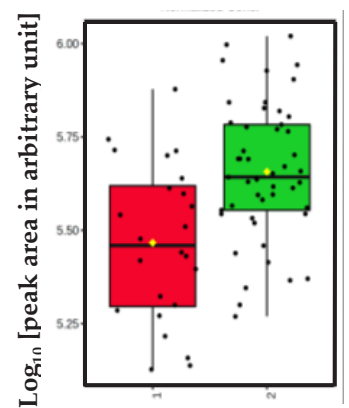

Creatine

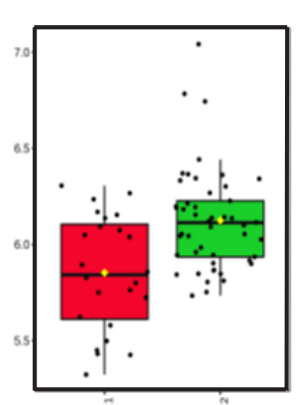

Betaine

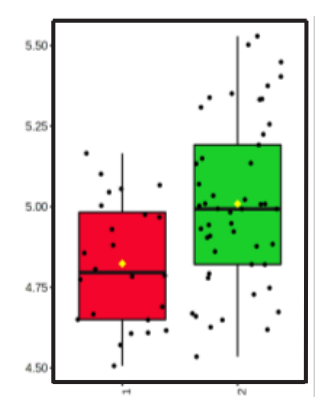

Pyruvate
B
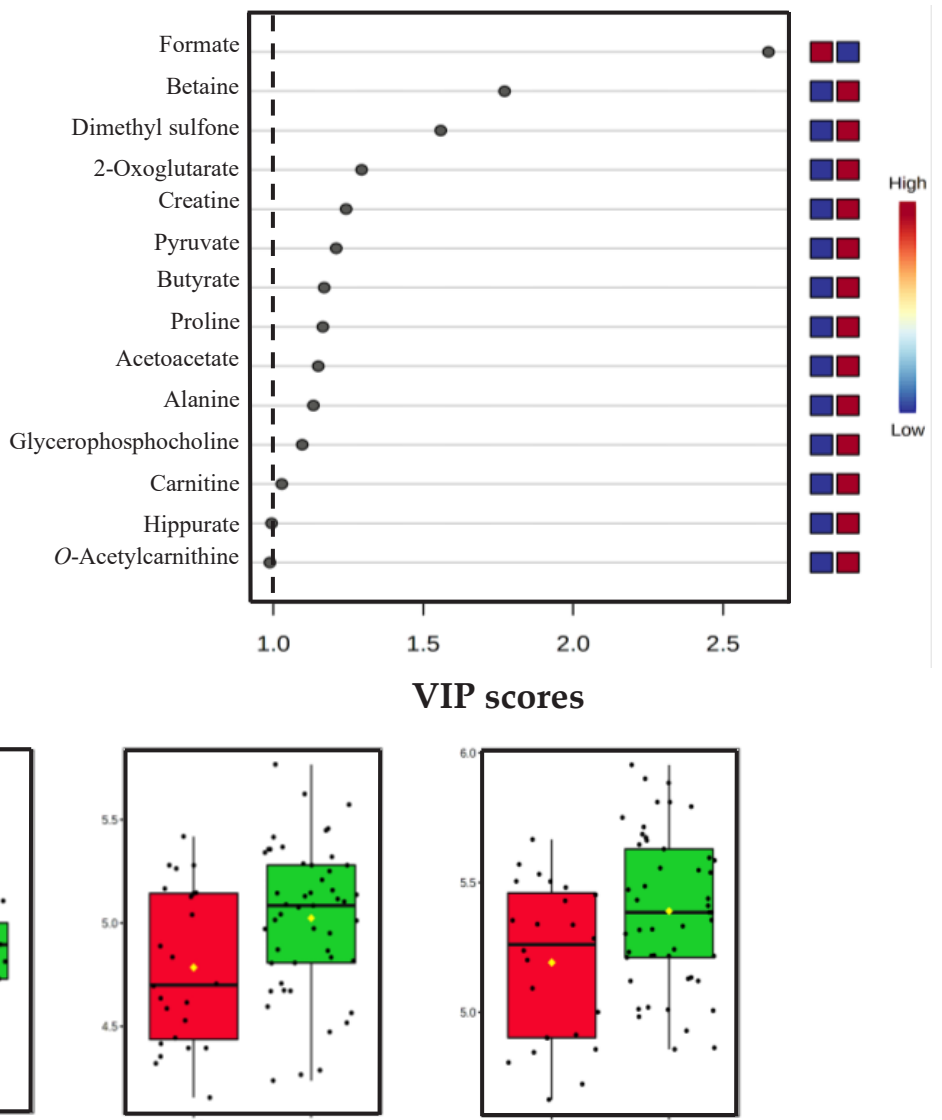

Dimethyl sulfone

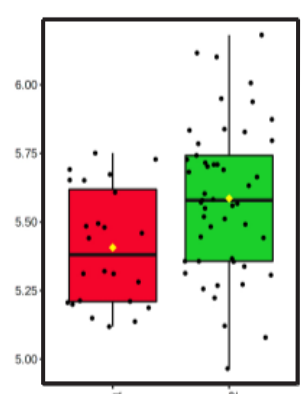

Butyrate

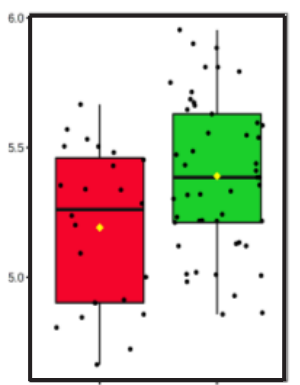

2-Oxoglutarate

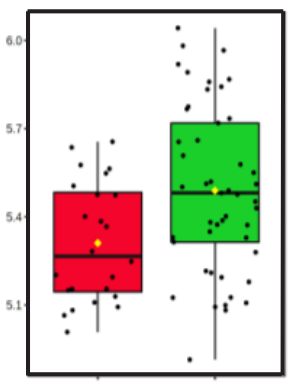

Proline

Figure 3. PLS-DA score plot (panel A) and VIP scores (panel B) for an overall comparison of ${ }^{1} \mathrm{H}-\mathrm{NMR}$ derived non-volatile polar metabolite profiles of conventional milk samples from brand A (O), brand B (-), brand C ( $)$, brand D (\$), brand E

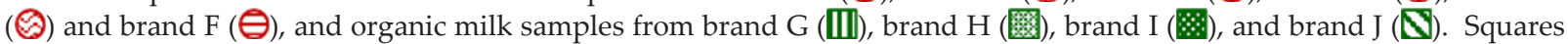
in the VIP score panel express normalized non-volatile polar metabolite content respected to the color range. The red color indicates higher content of the corresponding compound. Box-whisker plots represent comparative quantification of potential biomarker metabolites ( $\log _{10}$ [peak area of respective compound in arbitrary unit]) responsible for discrimination between organic $(\square)$ and conventional $(\square)$ milk samples (panel C). The lower and upper edge of the box denote $25^{\text {th }}$ and $75^{\text {th }}$ percentile of observation, respectively; the bold line within box denotes median value; the yellow-spot within box denotes average value; whiskers denote $5^{\text {th }}$ and $95^{\text {th }}$ percentiles. For interpretation of the references to color in this figure, the reader is referred to the web version of this article and the relative quantification of metabolites in Table 2.

pattern among the four brands of organic milk products could be demonstrated by PLS-DA. However, it seemed that several samples from brand G and I, particularly those located in quartiles 2 and 3 of the plot, owned distinctive ${ }^{1} \mathrm{H}-\mathrm{NMR}$ metabolite profiles apart from the other organic milk samples (Figure 4B).

\section{DISCUSSION}

The fat and protein contents of retail milk samples reported in this study were compliant with the Thai Ministry of Public Health Notification for Cow's Milk standard, which notifies that the fat and protein con- 
A

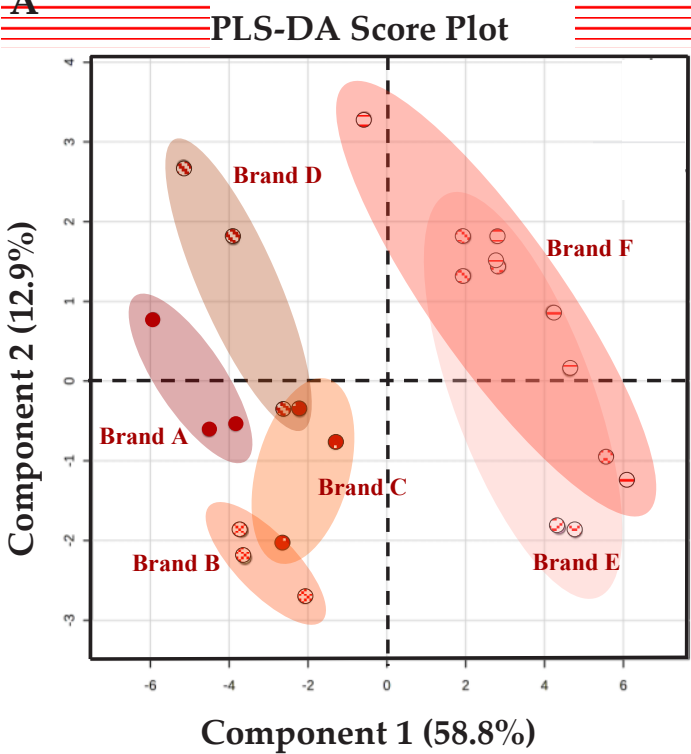

B

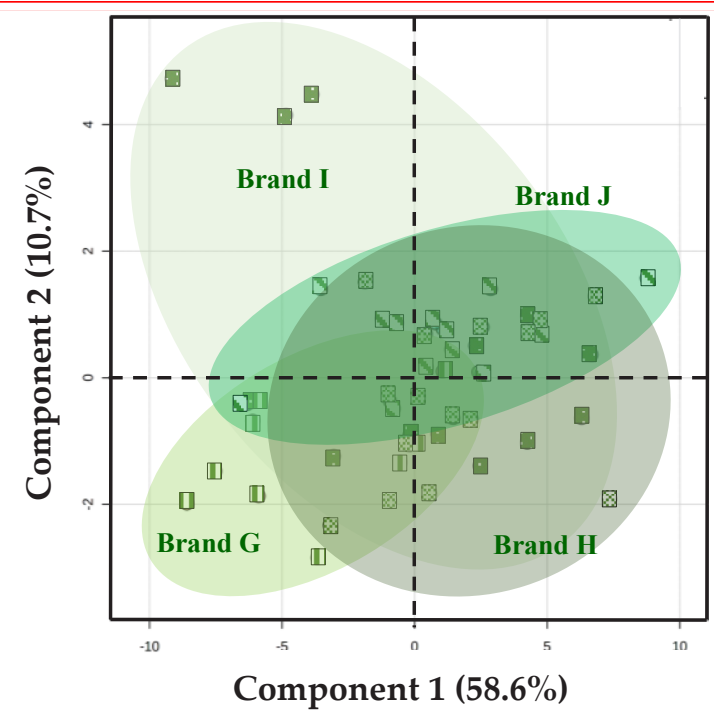

Figure 4. PLS-DA score plots for comparison of ${ }^{1} \mathrm{H}$-NMR derived non-volatile polar metabolite profiles within the group of conventional milk samples from brand A (O), brand B (1), brand C (9), brand D (\$), brand E (2) and brand $F(\theta)$ (panel A) and within the group of organic milk samples from brand $\mathrm{G}(\mathrm{II})$ ), brand $\mathrm{H}$ (國), brand I (庶), and brand J $(\mathbf{\nabla})$ (panel B). For interpretation of the references to color in this figure, the reader is referred to the web version of this article.

tents of commercial plain liquid milk should be higher than $3.20 \%$ and $2.80 \%$ (wt.), respectively (Ministry of Public Health (Thailand), 2013). The $\mathrm{pH}$ values of samples were also in the normal range of liquid milk (6.60-6.80) (National Bureau of Agricultural Commodity and Food Standards (Thailand), 2010). Although significant differences in gross composition among samples were remarkable, no distinctive pattern between organic and conventional milk products could be recognized. Generally, alterations in milk fat content are primarily influenced by animal diets, whereas protein content is mostly dependent on animal breeds and feed supplements (Walker et al., 2004). Variations in these two major milk components could be expected due to different feeding regimens and farming practices between organic and conventional dairy production systems. However, results from many studies have shown that differences in total fat and protein contents between organic and conventional milk are still ambiguous and could not be solely considered (Schwendel et al., 2015). In our case, when the retail products were investigated, differences can be also diverse due to milk standardization and compositional adjustment by specific dairy manufacturers.

To date, non-targeted NMR-based metabolomics has been extensively applied for monitoring the quality and authenticity of milk and dairy products (Balthazar et al., 2021). The list of identified metabolites in our study (45 compounds) were in agreement with those reported in bovine milk by other publications using a high-resolution ${ }^{1} \mathrm{H}-\mathrm{NMR}$ platform (500-600 MHz.) (Foroutan et al., 2019; Li et al., 2017; Luangwilai et al., 2021; Sundekilde et al., 2013). Results from chemometric analysis using HCA and PLS-DA demonstrated a good distinction between organic and conventional milk sam- ples based on their ${ }^{1} \mathrm{H}-\mathrm{NMR}$ metabolite profiles (Figure 2 and $3 \mathrm{~A})$. A complete distinction in retail milk metabolome between the two production systems was not always achievable, as also reported in the other studies (Boudonck et al., 2009; Erich et al., 2015). However, the $R^{2}$ and $Q^{2}$ values suggested good accuracy and well predictability of the PLS model. VIP scores derived from PLS-DA suggested that variations in the concentration of formate, betaine, dimethyl sulfone, 2-oxoglutarate, creatine, pyruvate, butyrate, proline, acetoacetate, alanine, glycerophosphocholine, carnitine, and hippurate could be used as potential biomarkers for discrimination between organic and conventional retail milk in this study (VIP > 1.0; $\mathrm{p}<0.05$ ) (Figure 3B). Besides loads of publication focusing on changes in milk fatty acid composition, alterations in the concentration of nonvolatile polar milk metabolites have also been found to be associated with the cow's physiology, animal diets, and farming practices in the organic dairy production system (Boudonck et al., 2009; O'Callaghan et al., 2018).

Our results demonstrated significantly higher abundances of dimethyl sulfone, creatine, butyrate, carnitine, and hippurate in organically produced milk which were corresponded well with kinds of literature (Boudonck et al., 2009; Magan et al., 2019; O'Donnell et al., 2010; O'Callaghan et al., 2018). It has been documented that dimethyl sulfone is generated from the oxidation of dimethyl sulfide derived from sulfur amino acid catabolism, particularly methionine, in the cow's rumen (Villeneuve et al., 2013). This metabolite has been linked to fresh grass diets, which are rich in dietary crude proteins in pasture and organic feedings and may notably influence the sensory profile of products due to its low odor threshold (Villeneuve et al., 2013). Butyrate is a short-chain fatty acid produced by the fermentation of 
carbohydrates and dietary fibers in the cow's rumen. A significant increase of butyrate in organically produced milk and retail products has been reported (O'Donnell et al., 2010; Schwendel et al., 2015). This metabolite is a key precursor for de novo synthesis of fatty acids in the mammary glands and therefore provides significant influences on the fatty acid composition between organic and conventional milk (Schwendel et al., 2015). The prevalence of short-chain fatty acids has been correlated with an increase of 2-oxoglutarate in milk (Faulkner \& Clapperton, 1981). Indeed, 2-oxoglutarate, also called $\alpha$-ketoglutarate, is an intermediate metabolite in the tricarboxylic acid (TCA) cycle of pyruvate metabolism. Significantly higher content of this compound in organic milk suggested that the TCA cycle was upregulated with more functional energy metabolism in the cow's mammary glands (Xi et al., 2017). Hippurate is commonly derived from the degradation of polyphenol-rich components in animal diets by the activity of rumen microbiota. This metabolite is absorbed, transported to the cow's liver, and then excreted in urine and milk (Lees et al., 2013). An increase in the concentration of hippurate in milk has been positively correlated with grazing pasture and fresh forage diets in the organic dairy production system (Boudonck et al., 2009; O'Callaghan et al., 2018). Possible application of $\delta^{15} \mathrm{~N}$ of certain amino acids such as phenylalanine, serine, and threonine for organic milk authentication was reported in the study of Chung et al. (2019). However, different biomarkers, i.e., proline and alanine, were statistically suggested in our study. Betaine is an amino acid-derived metabolite widely used as a supplement to improve milk production and rumen fermentation of dairy cows raised under heat stress condition (Shah et al., 2020). The concentration of betaine in milk could be varied according to animal dietary sources (Magan et al., 2019). Furthermore, it has been acknowledged that high abundances of energy metabolites and metabolic related compounds, i.e., pyruvate, acetoacetate, glycerophosphocholine, creatine, and carnitine, are associated with health, wellness, and physiological status of the cows (Klein et al., 2012; Lu et al., 2013; Schwendel et al., 2015; Sun et al., 2015; Xu et al., 2020) which can be certainly influenced by organic dairy production system.

On the other hand, formate was the only metabolite present in a relatively higher abundance in conventional milk samples. Although the high amount of formate could be associated with a high number of bacterial loads and somatic cell counts (SCC) in raw milk (Luangwilai et al., 2021), most studies have found no significant difference in mastitis incidence between organic and conventional dairy farming systems (Schwendel et al., 2015). According to the company's reputation, we believe that all samples were processed using bulk raw milk with at least an acceptable quality according to Thai ACFS standards (National Bureau of Agricultural Commodity and Food Standards (Thailand), 2010). A significantly higher amount of formate in cow's rumen fluid related to fresh forage diets in pasture feedings was reported by O'Callaghan et al. (2018). However, these authors found no significant rise in formate content in milk ( $\mathrm{O}^{\prime}$ Callaghan et al., 2018). It has been documented that intense heat treatment of milk could induce the conversion of lactose into a certain amount of formate (Trimigno et al., 2020). Based on product labels, most conventional milk samples in this study were ultra-pasteurized or extended shelf-life (ESL) products, while organic milk samples were HTST pasteurized products, perhaps due to their healthier and better fresh image. Furthermore, formic acid is widely used as a preservative in livestock feed and might be transferred from feed into milk (Dursun et al., 2017). In organic dairy production, the application of preservatives in animal feedstuffs and silages might be limited (National Bureau of Agricultural Commodity and Food Standards (Thailand), 2011). This could be a possible explanation for the higher abundance of formate detected in conventional milk samples in this study.

Variations among ${ }^{1} \mathrm{H}-\mathrm{NMR}$ metabolite profiles of milk samples from different brands within the same type of products were statistically evaluated and visualized in two separated PLS-DA (Figure 4). Distinctions among the ${ }^{1} \mathrm{H}-\mathrm{NMR}$ metabolite profiles of conventional milk samples could be remarkably observed with relatively high accuracy and predictability of the PLS model (Figure 4A). Based on product specification, samples from brand C and D were sold with a "premium quality" label by which higher standards for dairy production at farm level, i.e., GAP and traceability, and the quality of raw milk, i.e., microbial loads, SCC, fat, protein, and SnF contents, where required. Although the ${ }^{1} \mathrm{H}-\mathrm{NMR}$ metabolite profiles of samples from brands $\mathrm{E}$ and $\mathrm{F}$ were clearly distinguished from the other samples, the separation between these two brands could not be attained (Figure 4A). Indeed, it was remarkable that their metabolite profiles were relatively comparable with those of organic milk samples (Figure 2 and 3A). After consulting the company profiles, a hypothesis for this could be that these companies might use bulk raw milk collected in the central part of Thailand, where the majority of certified organic dairy farms are also located. This information suggests that factors other than the organic vs. conventional farming system, perhaps related to the geographical origin of raw milk, should also significantly impact the ${ }^{1} \mathrm{H}-\mathrm{NMR}$ metabolite profiles of retail products. Apparently, such factors did overcome the effect of the organic vs. conventional farming system on the metabolome of retail milk samples from brands $\mathrm{E}$ and F. The PLS-DA pattern shown in Figure 4B revealed a poor distinction among the ${ }^{1} \mathrm{H}-\mathrm{NMR}$ metabolite profiles of organic milk samples from the four brands with fair accuracy but poor predictability of the PLS model. It should be mentioned that certified organic milk products available in the Thai marketplace are traded exclusively by these leading dairy manufacturers where raw milk supplied in their production is mostly derived from organically certified dairy herds raised in the central part of the country (Thongplew et al., 2016). This information somehow supports the hypothesis regarding possible influences of factors related to the geographical origin of raw milk on the ${ }^{1} \mathrm{H}-\mathrm{NMR}$ metabolite profiles of retail products mentioned above.

Our findings support the effectiveness of using a non-targeted ${ }^{1} \mathrm{H}-\mathrm{NMR}$ combined with chemometric 
analysis to investigate the molecular authenticity of organic retail milk products available in the Thai marketplace. However, this work was exploratory with a limited number of samples and considered solely organic vs. conventional status of products based on the "Organic Thailand" certification emblem. In contrast, the complexity of factors influencing milk composition, especially those involved in primary production, was optimistically overlooked. For further validation, the complication between and within organic and conventional dairy production systems in terms of animal herds, feeding regimens, farming practices, geographically related environments, along with sufficient sample size and sampling period, should also be taken into consideration. From a metabolomics viewpoint, integrating non-volatile polar metabolite data with fatty acid composition could provide a complete overview of the molecular fingerprint of milk produced organically. Moreover, levels of trace hormonal composition and antibiotic residues should also be determined. Understanding dynamic changes of organic milk metabolome from the stage of raw milk, through thermal processing, until the end of product shelf-life is another key perspective that is essentially required. After a proper validation, this information could be eventually applied to establish a reliable predictive model with indicative metabolites for quality monitoring, authentication, and traceability of organic retail milk products in the future.

\section{CONCLUSION}

This study demonstrated an application of a nontargeted ${ }^{1} \mathrm{H}-\mathrm{NMR}$ metabolomics approach for molecular discrimination between organic and conventional liquid milk products sold in Thailand. Although there was no clear distinction between the two types of milk products in terms of major chemical composition, good discrimination could be observed based on their ${ }^{1} \mathrm{H}-\mathrm{NMR}$ metabolite fingerprints. Potential biomarker metabolites accountable for the discrimination between organic and conventional milk samples were statistically identified. Changes in the relative concentration of these indicative metabolites might reflect animal diets, rumen fermentation, and physiological adaptation of the cows raised in organic dairy farming systems.

\section{CONFLICT OF INTEREST}

The authors declare no conflict of interest.

\section{ACKNOWLEDGEMENT}

This research was financially supported by the $90^{\text {th }}$ Anniversary of Chulalongkorn University, Ratchadaphiseksomphot Endowment Fund. Technical assistance by BSc students in FTCU Dairy Research Group were highly appreciated.

\section{REFERENCES}

Balthazar, C. F., J. T. Guimarães, R. S. Rocha, T. C. Pimentel, R. P. C. Neto, M. I. B. Tavares, J. S. Graça, E. G. Alves Filho, M. Q. Freitas, E. A. Esmerino, D. Granato, S.
Rodrigues, R. S. L. Raices, M. C. Silva, A. S. Sant'Ana, \& A. G. Cruz. 2021. Nuclear magnetic resonance as an analytical tool for monitoring the quality and authenticity of dairy foods. Trends Food Sci. Technol. 108:84-91. https://doi. org/10.1016/j.tifs.2020.12.011

Boudonck, K., M. Mitchell, J. Wulff, \& J. Ryals. 2009. Characterization of the biochemical variability of bovine milk using metabolomics. Metabolomics 5:375-386. https:// doi.org/10.1007/s11306-009-0160-8

Capuano, E., R. Boerrigter-Eenling, G. van der Veer, \& S. M. van Ruth. 2013. Analytical authentication of organic products: An overview of markers. J. Sci. Food Agric. 93:12-28. https:// doi.org/10.1002/jsfa.5914

Capuano, E., R. Gravink, R. Boerrigter-Eenling, \& S. M. van Ruth. 2015. Fatty acid and triglycerides profiling of retail organic, conventional and pasture milk: Implications for health and authenticity. Int. Dairy J. 42:58-63. https://doi. org/10.1016/j.idairyj.2014.11.002

Chung, I. M., J. K. Kim, C. T. Yarnes, Y. J. An, C. Kwon, S. Y. Kim, Y. J. Yang, H. Y. Chi, \& S. H. Kim. 2019. Fatty acid- and amino acid-specific isotope analysis for accurate authentication and traceability in organic milk. J. Agric. Food Chem. 67:711-722. https://doi.org/10.1021/acs.jafc.8b05063

Dursun, A., Z. Güler, \& Y. E. Şekerli. 2017. Characterization of volatile compounds and organic acids in ultra-high-temperature milk packaged in tetra brik cartons. Int. J. Food Prop. 20:1511-1521. https://doi.org/10.1080/10942912.2016.1213280

Erich, S., S. Schill, E. Annweiler, H. U. Waiblinger, T. Kuballa, D. W. Lachenmeier, \& Y.B. Monakhova. 2015. Combined chemometric analysis of ${ }^{1} \mathrm{H}-\mathrm{NMR},{ }^{13} \mathrm{C}-\mathrm{NMR}$ and stable isotope data to differentiate organic and conventional milk. Food Chem. 188:1-7. https://doi.org/10.1016/j. foodchem.2015.04.118

Faulkner, A. \& J. L. Clapperton. 1981. Changes in the concentration of some minor constituents of milk from cows fed low- or high-fat diets. Comp. Biochem. Physiol. A Physiol. 68:281-283. https://doi.org/https://doi. org/10.1016/0300-9629(81)90355-8

Foroutan, A., A. C. Guo, R. Vazquez-Fresno, M. Lipfert, L. Zhang, J. Zheng, H. Badran, Z. Budinski, R. Mandal, B. N. Ametaj, \& D. S. Wishart. 2019. Chemical composition of commercial cow's milk. J. Agric. Food Chem. 67:4897-4914. https://doi.org/10.1021/acs.jafc.9b00204

Foroutan, A., C. Fitzsimmons, R. Mandal, H. Piri-moghadam, J. Zheng, A. Guo, C. Li, L. L. Guan, \& D. S. Wishart. 2020. The bovine metabolome. Metabolites 10:1-26. https://doi. org/10.3390/metabo10060233

Goldansaz, S. A., A. C. Guo, T. Sajed, M. A. Steele, G. S. Plastow, \& D. S. Wishart. 2017. Livestock metabolomics and the livestock metabolome: A systematic review. PLoS ONE 12:Article No. e0177675. https://doi.org/10.1371/journal.pone. 0177675

Klein, M. S., N. Buttchereit, S. P. Miemczyk, A.-K. Immervoll, C. Louis, S. Wiedemann, W. Junge, G. Thaller, P. J. Oefner, \& W. Gronwald. 2012. NMR metabolomic analysis of dairy cows reveals milk glycerophosphocholine to phosphocholine ratio as prognostic biomarker for risk of ketosis. J. Proteome Res. 11:1373-1381. https://doi.org/10.1021/ pr201017n

Lees, H. J., J. R. Swann, I. D. Wilson, J. K. Nicholson, \& E. Holmes. 2013. Hippurate: The natural history of a mammalian-microbial cometabolite. J. Proteome Res. 12:1527-1546. https://doi.org/10.1021/pr300900b

Li, Q., Z. Yu, D. Zhu, X. Meng, X. Pang, Y. Liu, R. Frew, H. Chen, \& G. Chen. 2017. The application of NMR-based milk metabolite analysis in milk authenticity identification. J. Sci. Food Agric. 97:2875-2882. https://doi.org/10.1002/jsfa.8118

Liu, N., A. M. Pustjens, S. W. Erasmus, Y. Yang, K. Hettinga, \& S. M. van Ruth. 2020. Dairy farming system markers: The correlation of forage and milk fatty acid profiles from organic, 
pasture and conventional systems in the Netherlands. Food Chem. 314:Article No. 126153. https://doi.org/10.1016/j. foodchem.2019.126153

Lu, J., E. Antunes Fernandes, A. E. Paez Cano, J. Vinitwatanakhun, S. Boeren, T. van Hooijdonk, A. van Knegsel, J. Vervoort, \& K. A. Hettinga. 2013. Changes in milk proteome and metabolome associated with dry period length, energy balance, and lactation stage in postparturient dairy cows. J. Proteome Res. 12:3288-3296. https://doi.org/10.1021/pr4001306

Luangwilai, M., K. Duangmal, N. Chantaprasarn, \& S. Settachaimongkon. 2021. Comparative metabolite profiling of raw milk from subclinical and clinical mastitis cows using ${ }^{1} \mathrm{H}-\mathrm{NMR}$ combined with chemometric analysis. Int. J. Food Sci. Tech. 56:493-503. https://doi.org/10.1111/ijfs.14665

Magan, J. B., T. F. O'callaghan, J. Zheng, L. Zhang, R. Mandal, D. Hennessy, M. A. Fenelon, D. S. Wishart, A. L. Kelly, \& N. A. McCarthy. 2019. Impact of bovine diet on metabolomic profile of skim milk and whey protein ingredients. Metabolites 9. https://doi.org/10.3390/metabo9120305

Ministry of Public Health (Thailand). 2013. Notification of the Ministry of Public Health (No. 350): Cow's milk (Version 2013). $\quad$ http://food.fda.moph.go.th/law/data/announ moph/V.English/No.350-56_cow_milk.pdf. [20 December 2020].

National Bureau of Agricultural Commodity and Food Standards (Thailand). 2010. Thai Agricultural Standard (TAS 6003-2010): Raw cow milk. https://www.acfs.go.th/ files/files/commodity-standard/20190607132619_234365. pdf. [20 December 2020].

National Bureau of Agricultural Commodity and Food Standards (Thailand). 2011. Thai Agricultural Standard (TAS 9000-2011): Organic agriculture part II: Organic livestock. http://www.acfs.go.th/standard/download/ ORGANIC-PART-2_LIVESTOCK_2554.pdf. [19 April 2021].

O'Donnell, A. M., K. P. Spatny, J. L. Vicini, \& D. E. Bauman. 2010. Survey of the fatty acid composition of retail milk differing in label claims based on production management practices. J. Dairy Sci. 93:1918-1925. https://doi.org/10.3168/ jds.2009-2799

O'Callaghan, T. F., R. Vázquez-Fresno, A. Serra-Cayuela, E. Dong, R. Mandal, D. Hennessy, S. McAuliffe, P. Dillon, D. S. Wishart, C. Stanton, \& R.P. Ross. 2018. Pasture feeding changes the bovine rumen and milk metabolome. Metabolites 8: Article No. 27. https://doi.org/10.3390/ metabo8020027

Rocchetti, G., A. Gallo, M. Nocetti, L. Lucini, \& F. Masoero. 2020. Milk metabolomics based on ultra-high-performance liquid chromatography coupled with quadrupole time-of-flight mass spectrometry to discriminate different cows feeding regimens. Food Res. Int. 134: Article number 109279. https:// doi.org/10.1016/j.foodres.2020.109279

Schwendel, B. H., T. J. Wester, P. C. H. Morel, M. H. Tavendale, C. Deadman, N. M. Shadbolt, \& D. E. Otter. 2015. Invited review: Organic and conventionally produced milk-An evaluation of factors influencing milk composition. J. Dairy Sci. 98:721-746. https://doi.org/10.3168/jds.2014-8389

Settachaimongkon, S., N. Wannakajeepiboon, P. Arunpunporn, W. Mekboonsonglarp, \& D. Makarapong. 2021. Changes in bovine colostrum metabolites during early postpartum period revealed by ${ }^{1} \mathrm{H}-\mathrm{NMR}$ metabolomics approach. Trop. Anim. Sci. J. 44: 229-239. https://doi.org/10.5398/ tasj.2021.44.2.229

Settachaimongkon, S., M. J. R. Nout, E. C. Antunes Fernandes, K. A. Hettinga, J. M. Vervoort, T. C. M. van Hooijdonk, M. H. Zwietering, E. J. Smid, \& H. J. F. van Valenberg. 2014. Influence of different proteolytic strains of Streptococcus thermophilus in co-culture with Lactobacillus delbrueckii subsp. bulgaricus on the metabolite profile of set-yoghurt. Int. J. Food Microbiol. 177:29-36. https://doi.org/http://dx.doi. org/10.1016/j.ijfoodmicro.2014.02.008
Settachaimongkon, S., H. J. F. van Valenberg, \& E. J. Smid. 2017. Metabolomics as an Emerging Strategy for the Investigation of Yogurt Components. In N. P. Shah (Ed.). Yogurt in Health and Disease Prevention. Academic Press, London. pp. 427449. https://doi.org/10.1016/B978-0-12-805134-4.00025-0

Shah, A. M., J. Ma, Z. Wang, H. Zou, R. Hu, \& Q. Peng. 2020. Betaine supplementation improves the production performance, rumen fermentation, and antioxidant profile of dairy cows in heat stress. Animals 10:634. https://doi.org/10.3390/ ani10040634

Smigic, N., I. Djekic, I. Tomasevic, N. Stanisic, A. Nedeljkovic, V. Lukovic, \& J. Miocinovic. 2017. Organic and conventional milk - insight on potential differences. Br. Food J. 119:366376. https://doi.org/10.1108/BFJ-06-2016-0237

Sun, H. Z., D. M. Wang, B. Wang, J. K. Wang, H. Y. Liu, L. L. Guan, \& J. X. Liu. 2015. Metabolomics of four biofluids from dairy cows: Potential biomarkers for milk production and quality. J. Proteome Res. 14:1287-1298. https://doi. org/10.1021/pr501305g

Sundekilde, U. K., N. A. Poulsen, L. B. Larsen, \& H. C. Bertram. 2013. Nuclear magnetic resonance metabonomics reveals strong association between milk metabolites and somatic cell count in bovine milk. J. Dairy Sci. 96:290-299. https://doi. org/http://dx.doi.org/10.3168/jds.2012-5819

Tenori, L., C. Santucci, G. Meoni, V. Morrocchi, G. Matteucci, \& C. Luchinat. 2018. NMR metabolomic fingerprinting distinguishes milk from different farms. Food Res. Int. 113:131139. https://doi.org/10.1016/j.foodres.2018.06.066

Thongplew, N., C. S. A. Kris van Koppen, \& G. Spaargaren. 2016. Transformation of the dairy industry toward sustainability: The case of the organic dairy industries in the Netherlands and Thailand. Environ. Dev. 17:6-20. https:// doi.org/10.1016/j.envdev.2015.11.005

Trimigno, A., C. B. Lyndgaard, G. A. Atladóttir, V. Aru, S. B. Engelsen, \& L. K. H. Clemmensen. 2020. An NMR metabolomics approach to investigate factors affecting the yoghurt fermentation process and quality. Metabolites 10:1-16. https://doi.org/10.3390/metabo10070293

Tsiafoulis, C. G., C. Papaemmanouil, D. Alivertis, O. Tzamaloukas, D. Miltiadou, S. Balayssac, M. MaletMartino, \& I. P. Gerothanassis. 2019. NMR-based metabolomics of the lipid fraction of organic and conventional bovine milk. Molecules 24:Article number 1067. https://doi. org/10.3390/molecules24061067

Vallverdú-Queralt, A. \& R. M. Lamuela-Raventós. 2016. Foodomics: A new tool to differentiate between organic and conventional foods. Electrophoresis 37:1784-1794. https:// doi.org/10.1002/elps.201500348

Villeneuve, M. P., Y. Lebeuf, R. Gervais, G. F. Tremblay, J. C. Vuillemard, J. Fortin, \& P. Y. Chouinard. 2013. Milk volatile organic compounds and fatty acid profile in cows fed timothy as hay, pasture, or silage. J. Dairy Sci. 96:7181-7194. https://doi.org/10.3168/jds.2013-6785

Walker, G. P., F. R. Dunshea, \& P.T. Doyle. 2004. Effects of nutrition and management on the production and composition of milk fat and protein: A review. Aust. J. Agric. Res. 55:10091028. https://doi.org/10.1071/AR03173

Wishart, D. S. 2008. Metabolomics: applications to food science and nutrition research. Trends Food Sci. Technol. 19:482493. https://doi.org/10.1016/j.tifs.2008.03.003

Xi, X., L. Y. Kwok, Y. Wang, C. Ma, Z. Mi, \& H. Zhang. 2017. Ultra-performance liquid chromatography-quadrupoletime of flight mass spectrometry MSE-based untargeted milk metabolomics in dairy cows with subclinical or clinical mastitis. J. Dairy Sci. 100:4884-4896. https://doi.org/10.3168/ jds.2016-11939

Xu, W., A. Van Knegsel, E. Saccenti, R. Van Hoeij, B. Kemp, \& J. Vervoort. 2020. Metabolomics of milk reflects a negative energy balance in cows. J. Proteome Res. 19:2942-2949. https:// doi.org/10.1021/acs.jproteome.9b00706 